\title{
Retraction Note to: Experimental study on the mechanical properties of unsaturated soils and the effects of dry-wet cycles-taking coastal cities as examples
}

\author{
Qinghai Zhang ${ }^{1} \cdot$ Mingbao $\mathrm{Li}^{2} \cdot \mathrm{Lihua} \mathrm{Wu}^{1}$
}

Published online: 6 December 2021

(c) Saudi Society for Geosciences 2021

Retraction Note to: Arabian Journal of Geosciences (2021) 14: 1768 https://doi.org/10.1007/s12517-021-08071-6

The Editor-in-Chief and the Publisher have retracted this article because the content of this article is nonsensical. The peer review process was not carried out in accordance with the Publisher's peer review policy. The authors have not responded to correspondence regarding this retraction.

The original article can be found online at https://doi.org/10.1007/ s12517-021-08071-6.

Qinghai Zhang

zqh464354668@163.com

1 Suihua School, Agriculture and Hydraulic Engineering University, Suihua 152000, Heilongjiang, China

2 School of Civil Engineering, Northeast Forestry University, Harbin 150040, Heilongjiang, China 